\title{
EL CICLO MORTAL \\ DE LOS HABITANTES DE CALLE \\ EN BOGOTÁ. TEORÍAS, OLVIDOS, POLÍTICAS Y DESENLACES FATALES
}

Óscar A. Alfonso R. ${ }^{a}$

Rafael A. Barrera $G$. $^{\mathrm{b}}$

Pedro I. Bernal F.

Diana C. Camargo C. ${ }^{\mathrm{d}}$

Laura C. Garzón B. ${ }^{\mathrm{e}}$

* DOI: https://doi.org/10.18601/01245996.v21n41.05. Recepción: 08-082018, modificación final: 01-04-2019, aceptación: 14-05-2019. Sugerencia de citación: Alfonso R., Ó., Barrera, R. A. et al. (2019). El ciclo mortal de los habitantes de la calle en Bogotá. Teorías, olvidos, políticas y desenlaces fatales. Revista de Economia Institucional, 21(41), 99-131.

a Doctor en Planeamiento Urbano y Regional. Docente-investigador, Facultad de Economía, Universidad Externado de Colombia, Bogotá, Colombia, [oscar.alfonso@uexternado.edu.co], [https://orcid.org/0000-0003-0781-0658].

b Magister en Economía. Profesor de la Escuela Colombiana de Ingeniería y del Colegio Mayor de Cundinamarca, Bogotá, Colombia, [randresbg@ yahoo.com], [https://orcid.org/0000-0001-7773-8984].

c DOA en Políticas Públicas y Ordenamiento Territorial. Docente-investigador, Facultad de Economía, Universidad Externado de Colombia, Bogotá, Colombia, [pedro.bernal@uexternado.edu.co], [https://orcid.org/0000-00016903-6966].

d Estudiante de Economía. Investigadora, Facultad de Economía, Universidad Externado de Colombia, Bogotá, Colombia, [diana.camargo02@est. uexternado.edu.co], [https://orcid.org/0000-0001-5413-1784].

e Estudiante de Economía. Investigadora, Facultad de Economía, Universidad Externado de Colombia, Bogotá, Colombia, [laura.garzon07@est.uexternado.edu.co], [https://orcid.org/0000-0003-4588-6450]. 


\section{El ciclo mortal de los habitantes de calle en Bogotá. Teorías, olvidos, políticas y desenlaces fatales}

Resumen El fenómeno de la habitación de la calle es universal, si bien se presenta con mayor intensidad en las metrópolis tercermundistas. Un estado del arte reconstruido desde una perspectiva pluridisciplinar permite advertir ciertos olvidos acerca de sus determinantes. En este artículo se plantea la hipótesis de que la entrada a la habitación en la calle en Bogotá se realiza a cualquier edad y que, cuando ello ocurre, se anticipa la etapa de desesperanza con la que se inicia el ciclo mortal de las personas.

Palabras clave: adicción a sustancias, economía de las minorías, valor de la vida, equidad, justicia, desigualdad; JEL: J15, J17, D63

The deadly cycle of street dwellers in Bogotá. Theories, forgetting, policies and fatal outcomes

Abstract The deadly cycle of street dwellers in Bogotá Theories, forgetting, comparisons, policies and fatal outcomes The phenomenon of street homelessness is universal, although it occurs with greater intensity in the Third World metropolises. A state of the art reconstructed from a multidisciplinary perspective allows to notice certain forgetfulness about its determinants. This article hypothesizes that the entrance to habitability on the street in Bogotá takes place at any age, and that when this happens, the stage of despair with which the mortal cycle begins is anticipated.

Keywords: Substance addiction, minority economy, value of life, equity, justice, inequality; JEL: J15, J17, D63

\section{O ciclo mortal dos moradores de rua em Bogotá. Teorias, esquecimento, políticas e resultados fatais}

Resumo O fenômeno da moradia de rua é universal, embora ocorra com maior intensidade nas metrópoles terceiromundistas. Um estado da arte reconstruído a partir de uma perspectiva multidisciplinar permite perceber certo esquecimento de seus determinantes. Este artigo traz a hipótese de que a entrada na moradia de rua em Bogotá (Colômbia) ocorra em qualquer idade e que, quando isso acontece, se antecipa o estágio de falta de esperança com o qual começa o ciclo mortal das pessoas.

Palavras-chaves: dependência de substâncias, economia das minorias, valor da vida, equidade, justiça, desigualdade; JEL: J15, J17, D63 
- 1 abandono de menores de edad y de personas desvalidas es un Cdelito tipificado en el artículo 127 del Código Penal y declarado exequible en sentencias de la Corte Constitucional, como la C-034/05. Sin embargo, hay más de 10 mil personas abandonadas en las calles de Bogotá. Este artículo hace un balance crítico de algunos de los numerosos trabajos académicos que analizan el fenómeno de la habitación de la calle; describe el contenido de las políticas de los últimos gobiernos distritales, y aporta evidencia estadística en la que se apoya la hipótesis básica: que, desde una perspectiva psicológica del ciclo vital individual, los habitantes de calle de cualquier sexo y grupo de edad ingresan de manera precoz a la etapa de desesperanza con la que se inicia el ciclo mortal de las personas.

\section{HACIA UN ESTADO DEL ARTE PLURIDISCIPLINAR}

Nieto y Koller (2015) sintetizan la discusión internacional sobre la definición de habitante de calle y encuentran diferencias entre las definiciones propuestas en países desarrollados, países en desarrollo y las Naciones Unidas. Aunque la habitación en calle es un fenómeno social en muchos países y en varios momentos históricos, no hay un consenso sobre su definición. Las definiciones son variadas y no solo hay diferencias entre países sino incluso dentro de un mismo país.

Según los términos utilizados en las discusiones sobre la habitación en la calle de los países desarrollados, se puede afirmar que se trata de una definición circunscrita a la dimensión habitacional, operativa y funcional para los estudios cuantitativos y de enumeración, pero conceptualmente asociada a la dimensión social de dicha problemática (ibíd., p. 10).

En los países en desarrollo, las definiciones no han sido estables ni homogéneas, ni objeto de debate. Son amplias e incluyen tanto a quienes no habitan en una vivienda como a quienes viven en la calle o en instituciones de abrigo. Las definiciones de Naciones Unidas también son inestables y variadas, y enfocan el fenómeno desde una perspectiva habitacional, la calidad de la vivienda. Los niños en situación de calle se consideran como un subgrupo de habitantes de calle. La definición de niño, niña y adolescente en situación de calle también es heterogénea e inestable, con connotaciones políticas, y es objeto de discusión. La falta de consenso en la definición afecta la forma en que se caracteriza a los habitantes de calle, las comparaciones sobre la prevalencia de esta problemática entre países y los criterios para incluirlos en investigaciones, programas o políticas de intervención social. 


\section{LA DESIGUALDAD}

La desigualdad no solo se manifiesta en el ingreso de las personas sino también en el acceso a bienes y servicios inseparables de las funciones del Estado, y en prácticas discriminatorias en la esfera privada. Los habitantes de calle son el resultado humano más conspicuo de la desigualdad.Wilkinson y Pickett (2009) convienen en que la desigualdad dificulta la vida en comunidad, las relaciones sociales y la movilidad social. E1 igualitarismo no es una regla universal, y aun entre los más pobres es considerable la desigualdad en la percepción de los ingresos (Sen, 2011). Entre los pobres se encuentran aquellos cuyo ingreso no les permite acceder a los bienes que garanticen su consumo basal y menos aún su equilibrio nutricional. El costo de la canasta normativa de satisfactores básicos se denomina línea de indigencia, y queda por construir la línea de habitación en calle, que sería la de ingreso cero.

\section{JURIDICIDAD, PSICOANÁLISIS Y REPRESENTACIONES SOCIALES}

Báez, González y Fernández (2013) hacen una propuesta de investigación-intervención basada en la teoría psicoanalítica, donde el sujeto es el actor principal. La noción del sujeto que habita en la calle se acuñó en espacios de participación marcados por los discursos religiosos y del Estado de derecho y de deberes. Esto posibilitó la entrada del significante, aquel que interroga y permite la apertura del inconsciente para que sea el sujeto mismo quien encuentre un sentido a su decir. E1 acercamiento con el habitante de calle permitió que éste se reconociera así mismo y pudiera expresar a qué se hace referencia cuando se le denomina de esa manera, qué hace en las calles y por qué circula en ellas. Intentan comprender el fenómeno del habitar en la calle como un modo de subjetivación, donde el sujeto, por un lado, establece una particular forma de relación con otro sujeto y, por otro lado, una relación con el discurso mismo que lo sostiene, puesto que la visión del otro puede sesgarse por efecto de las diferentes interpretaciones y concepciones que se tienen del habitante de calle. Como resultado plantean que "quien habita en la calle no lo es, tanto, por el hecho de que viva o no en ella, sino de que exista en lo que implica el discurso de la calle, es decir, ser en la calle, decir desde la calle y hacer en la calle" (ibíd., p. 11); esto es, existe un sujeto consciente de la decisión de habitar en la calle que es responsable del lugar que ocupa, y que con ello da cuenta de la participación en un discurso que le permite su establecimiento en la calle. 
Gómez (2015) hace un análisis de las causas que originan la habitación en la calle, que subraya el punto de vista jurídico. Evoca el artículo $2^{\circ}$ de la Ley 1641 de 2013, que define al habitante de calle como "la persona sin distinción de sexo, raza o edad, que hace de la calle su lugar de habitación, ya sea de forma permanente o transitoria, y que ha roto vínculos con su entorno familiar". En un fallo de tutela de la Corte Constitucional, la diferencia entre el habitante de calle y el indigente radica en que el primero habita en el espacio público urbano, donde transcurre su vida y, por tanto, la falta de vivienda es lo que lo distingue del indigente. Uno de los aportes de este análisis es su fuente inspiradora, una investigación sobre la colisión entre derechos sociales y la libertad civil, surgida a raíz de un fallo de la Corte Constitucional por el cual el habitante de calle está en libertad de rechazar la asistencia social del Estado, y puede preferir mantenerse en la calle; aunque así opta por ignorar las causas que lo condujeron a esa situación. Seguidamente, Gómez propone una taxonomía de las causas originarias del estatus de habitante de calle basada en la jurisprudencia:

i) Las derivadas de razones internas: el habitante de calle es un resultado de problemas psicológicos, de salud y de conflictos de carácter privado como problemas familiares -o carencia de la misma-, que le impiden sostenerse económicamente y consecuentemente, la persona se ve despojada de su hogar; ii) las derivadas de la pobreza extrema y de la marginalidad: el habitante de calle es una representación de una sociedad desigual y excluyente; y, iii) las derivadas del conflicto armado: el habitante de calle como consecuencia del conflicto armado, y más específicamente del desplazamiento (ibíd, p. 31).

Esas causas pueden conjugarse en una misma persona, y es posible que dos o aun las tres causas determinen la condición de habitante de calle. No obstante, las razones que ocasionaron la ruptura de los vínculos con el entorno familiar, el principal determinante de la habitación en la calle, se estudian escasamente.

Con la expedición de la Ley 1641 de 2013, la población habitante de calle se reconoce como un grupo de atención y protección especial, que requiere una intervención estatal "coherente con sus realidades". El papel del Dane es crucial en la caracterización socioeconómica y demográfica de los habitantes de calle. Las entidades territoriales están obligadas a implementar políticas públicas basadas en la caracterización del Dane, siguiendo la secuencia formulación- implementación-seguimiento-evaluación de impacto. Dos años después de su expedición, la ley no se había implementado por una tardanza injustificada en la caracterización de los habitantes de calle, que en 
Bogotá se prolongó hasta 2017, y porque el gobierno nacional no había reglamentado la ley (Mendivelso, 2017, p. 10). Acudiendo al principio de igualdad y no discriminación, Mendivelso explica las razones jurídicas para la atención especial del Estado a los habitantes de calle, que son víctimas de trato discriminatorio, desigual e injusto (ibíd., pp. 11 y ss.). Las sentencias de la Corte Constitucional, comenzando por la T-533 de 1992 que cataloga la pobreza extrema -no tener los recursos mínimos para sobrevivir- como una de las principales causas que impiden llevar una vida digna (el caso de los habitantes de calle), se han orientado a restablecer los derechos fundamentales a personas que lo han perdido por habitar en las calles. La "arquimédica" sentencia T-043 decanta un largo recorrido en busca de un hilo jurisprudencial cuya finalidad es restablecer sus derechos, pero como dice Mendivelso, "la discusión que aquí podría suscitarse es que dicho restablecimiento aparece como la cura para los males sin [ninguna] medida preventiva para que un indigente no adquiera la calidad de habitante de calle cuando es susceptible de ello" (ibíd., p. 125).

Restrepo (2016) considera que problemas sociales como la marginalidad, la exclusión social y la disfunción familiar modifican las dinámicas políticas, económicas y culturales de las ciudades y de la vida urbana. Los habitantes de calle son un resultado de estas dinámicas, bien sea porque el sujeto decida elegir ese tipo de vida o porque la sociedad lo empuje a esa condición. En tal sentido, la exclusión social alienta la problemática de habitantes de calle, en cuanto son "los excluidos aquellos sujetos que han perdido su filiación con la población y no pueden integrarse y, por tanto, se sitúan fuera de las pautas de producción y consumo comúnmente admitidas por la sociedad" (Enríquez, 2007, p. 76, citado por Restrepo, 2016, p. 97). Por ello, el rechazo al estilo de vida, normas y valores de los habitantes de calle lleva a llamarlos 'ñeros', 'indigentes', 'desechables' y 'gamines' y, por ende, a excluirlos. Restrepo recalca la importancia de las representaciones sociales, que permiten entender las interacciones, vivencias y experiencias en las que se generan los diferentes contextos sociales. "En resumen el medio cultural en que viven las personas, el lugar que ocupan en la estructura social y las experiencias concretas con las que se enfrentan a diario influyen en su forma de ser, su identidad social y la forma en que perciben la realidad social" (Araya, 2002, p. 14, citado por Restrepo, 2016, p. 98).

La elección bajo incertidumbre es una preocupación central de los economistas conductuales que, como Kahneman y Tversky (1973), plantean que, en condiciones de incertidumbre, las recompensas se- 
guras moldean las decisiones como, por ejemplo, si en una situación ganar mucho es poco probable, las personas se inclinarán a perder poco. Desde una perspectiva psicológica, la incertidumbre es resultado de la cantidad limitada de representaciones que el individuo procesa, cuyo resultado es un juicio a partir del cual realiza sus elecciones. Las representaciones sociales permiten entender el contexto debido a que son: "organizadoras de la experiencia, reguladoras de la conducta y dadoras de valor" (Navarro y Gaviria, 2010, p. 347), y hacen posible la adaptación de los individuos a su propia realidad contextual y al grupo social al que pertenecen. Navarro y Gaviria (2010), motivados por el fenómeno de habitación en la calle como flagelo acompañado de exclusión social, marginalidad y estigmatización, lo estudiaron como objeto de representación. Abordaron a un centenar de personas a las que se les pidió que mencionaran las palabras que asociaban a la frase Habitante de calle, para acceder al espectro semántico asociado. El análisis de la representación social por medio de la interpretación de los resultados lexicográficos obtenidos de la muestra determinó que todas las percepciones obtenidas tenían connotaciones negativas asociadas a la condición social, la inseguridad, la salud mental, la apariencia física e incluso la supuesta relación con las drogas. Paradójicamente también se asociaban a la marginalidad socioeconómica, lo que indica una posible compasión suscitada por el conocimiento de las dificultades de los habitantes de calle.

Esta variedad de aproximaciones al fenómeno de la habitación en la calle, ocasionada por las perspectivas que adoptan los investigadores para revelar alguna dimensión que lo explique, dista de ser exhaustiva en cuanto a sus determinantes. En nuestra revisión detectamos al menos tres vacíos de trascendencia social y de utilidad para diseñar políticas de prevención y atención humanitaria, que se analizan a continuación. Un análisis más profundo es tema de próximos trabajos.

\section{FAMILIAS DISFUNCIONALES}

Los problemas cognitivos y de conducta que afrontan los seres humanos en algún momento de su vida requieren, como cualquier enfermedad, apoyo médico para superarlos. La ayuda terapéutica a personas con conflicto familiar pretende subsanar los problemas afectivos que padecen, y a prevenir los abusos a que están expuestas las más frágiles. La prevalencia de conductas disruptivas de la convivencia intrafamiliar es un determinante crucial para habitar en la calle cuando el miembro frágil opta por esa opción en vista del abuso a que es sometido por el más fuerte. 


\section{HIJOS INDESEADOS}

En las conductas asociales extremas de los habitantes de la calle, con su alto potencial de intimidación al transeúnte, se identifican retrasos cognitivos asociados a distorsiones de razonamiento, falta de sentimientos de reciprocidad y confianza, y la inexpresividad emocional que en ambientes intolerantes produce la agresividad. Estos rasgos se originan comúnmente en la interacción cotidiana entre miembros de familias disfuncionales, en las que el infante o el joven en transición a la adolescencia manifiesta hastío por el abuso del castigo al que es sometido por haber sido hijo indeseado, para doblegar su incipiente voluntad y lograr obediencia, o para imponerle las reglas de una moral que juzga incompatible con su visión del mundo. En ausencia de estímulos positivos con los que pueda advertir su inserción simbólica y real en la sociedad, y de acciones solidarias de otros familiares o amigos cercanos, la calle -con sus atractivos ocultos- es la única alternativa a una vida sin esas tensiones insoportables.

Corinne Maier (2017), madre titulada en economía y psicoanálisis, de orientación lacaniana, expresa las razones por las que "odia a los niños”. Comienza diciendo que son una carga para la vida, en especial para las madres que, como ella, perdieron parte de su libertad por la procreación y su dedicación a cuidar, educar y mantener a sus dos hijos. Para ella, los hijos atan a los padres a un sistema decadente, los obligan a aceptar trabajos aburridos para conseguir los ingresos necesarios para satisfacer la codicia de sus vástagos, lo que propicia inevitablemente una "paternidad consumista". Por ello, dice que la mayor felicidad de la maternidad ocurre cuando los hijos abandonan el hogar. Es el día para celebrar, ¡con champaña!

Cuando el hijo es una carga para los padres y ellos no esperan de él momentos de gozo, de amorosa interacción y no prevén un resarcimiento simbólico o real a sus sacrificios, el hogar se torna un sistema socio-ecológico estresante, donde el maltrato y la violencia intrafamiliar afloran como medios para resolver las diferencias. Los detonantes más comunes son el mal desempeño escolar del menor, las sospechas de consumo de alucinógenos y de conductas delictivas.

Las razones para el mal desempeño escolar suelen buscarse en el estudiante, no en el sistema educativo y en las formas de hacer escuela de sus miembros. La aspiración de un estudiante a desarrollar algún talento, en un ambiente académico que promueva la autonomía y la libertad, no es una búsqueda del pasado, sino el encuentro con un modo de vida que lo caracterice. La escuela que se opone a tal encuentro es un proyecto que impulsa algún énfasis basado en la entronización 
de los dictámenes del mercado laboral y de las demandas de la economía, y para ello impone currículos que pretenden homogeneizar a los estudiantes que terminan cada ciclo educativo. En ese ambiente, la rudeza de la memorización se impone sobre la excitación de la curiosidad, la reflexión y el pensamiento. El mal desempeño escolar suele originarse en la sensación de ser la parte dominada de un sistema represivo que no promueve su talento y que lo distancia de los demás miembros de su cohorte que, por alguna razón, se han sometido a las reglas del modelo, y lo acerca a otros grupos de contacto en rebeldía, aunque no necesariamente por iguales razones. Entre tales grupos están los conformados por quienes, incitados por terceros, creen que el consumo de alucinógenos libera del estrés, o por quienes promueven conductas delictivas para resarcirse de los daños causados por la sociedad que los excluye.

\section{MODELOS DE ESCUELA INCOMPATIBLES CON LA PROMOCIÓN DEL TALENTO}

A las expectativas de educarse de los jóvenes suelen oponerse los proyectos educativos en los que prima la imposición de criterios morales y dogmas, sobre la promoción del talento, algo que se asemeja a la restricción de capacidades discutida por Sen (2011). La persistencia de modelos educativos que, con la pretensión de ilustrar, difunden arcaísmos como la servidumbre natural, imponen reglas homogeneizadoras a un universo diverso, está asociada a visiones del mundo que se promueven de manera premeditada como parte de un proyecto de sociedad elitista. Cuando el joven percibe que su talento es reprimido, para someter su voluntad a las reglas del proyecto educativo, afloran tensiones que primero se manifiestan en indisciplina, luego por desinterés e inasistencia a las aulas, y terminan con el abandono. En ese momento el conflicto familiar se agudiza y los padres que comparten el proyecto educativo civilizatorio por haberse formado en él, porque su grupo social de referencia también lo es o porque simpatizan con el proyecto político que lo impulsa, tratan de imponerlo en el hogar. La comparación con los aprovechados hijos de otras familias exacerba la animadversión del joven talentoso hacia el entorno inmediato, se produce el abandono y llega a la calle.

\section{EL DESAHUCIO EN LA VEJEZ}

Así como hay niños que llegan a habitar la calle, también llegan personas adultas. En este grupo, las de mayor edad constituyen un problema social igualmente apremiante que tiende a agravarse con el 
incremento de las tasas de envejecimiento y la escasa o nula cobertura de un programa pensional o de renta básica para la mayor parte de los adultos mayores.

Los adultos mayores que son considerados como una carga por sus familiares -en particular por sus hijos adultos que manifiestan su intolerancia ante la conducta de quienes han llegado a la senectud- son repudiados por estar en un ciclo improductivo de duración incierta y, por ello, no ameritan gasto alguno pues el que hiciesen no tendrá retorno. En tal situación, la fragilidad de los vínculos familiares es arrasada por la racionalidad costo-beneficio, y el desahucio y el abandono sobrevienen al maltrato al que son sometidos. Parte de los adultos mayores indeseados es recibida en hogares geriátricos donde reciben cuidado a cambio de mensualidades que pagan los familiares, algunos de los cuales a veces los visitan. Algunas familias que no pueden pagar las mensualidades o que no están dispuestas a pagarlas, intentan que su responsabilidad sea asumida por el Estado internándolos en una entidad de beneficencia o en un asilo y, si no lo consiguen, los abandonan en lugares donde llamarán la atención: una sala de urgencias, un centro comercial o una terminal de transporte.

Un rasgo inquietante es que la mayor proporción de adultos mayores que llega a habitar en la calle son hombres. Algunos psicólogos ecuatorianos sostienen que tal proporción bordea el 70\% y que ello se debe, en especial, a cierto rasgo de la cultura patriarcal en la que los vínculos afectivos de los hijos se establecen con la madre, porque el padre proveedor del ingreso familiar siempre está ocupado o cansado para afianzarlos (Mosquera, 2012). Una relación tiránica entre padres e hijos aumenta la posibilidad de abandono y de desahucio en la vejez, ante la ausencia de sentimientos como el respeto o la solidaridad, aflorando en cambio el odio y la venganza. El desahucio ocurre a veces con el despojo subrepticio de los bienes del adulto mayor, orquestado en general por los hijos con auxilio de otros familiares quienes, recurriendo al engaño y a la suplantación, usurpan su propiedad, a sabiendas de que incurren en el delito de abandono agravado por el de defraudación mediante el abuso del adulto mayor en condiciones de inferioridad, prescritos en el capítulo sexto del título primero, y sexto y séptimo del título segundo del Código Penal.

\section{DESPLAZAMIENTO FORZADO}

En los Estados que han perdido el monopolio en el uso de la fuerza, y en los que abusan de ella, el propósito fundante de la preservación 
del imperio de la ley es relegado a un segundo plano por el embate de los que imponen sus criterios a sangre y fuego. E1 desarraigo que sobreviene, a fin de preservar la vida, es un determinante de la habitación en la calle cuando las víctimas no encuentran amparo en los lugares de destino.

\section{INTERNO}

La exagerada duración del conflicto armado amplía su cobertura territorial y, además, lo degrada. El mayor contingente de víctimas es la población que, en evidente estado de indefensión, es objeto de los grupos armados. El propósito estratégico de esos grupos es ensanchar su dominio territorial y desplazar al enemigo para facilitar sus acciones. La propiedad de los habitantes de las zonas rurales de esas regiones se convierte como el principal botín de una gesta desigual, cuyo fragor llama la atención de testigos que los violentos procuran silenciar. El despojo ilegal de la propiedad con amenazas de muerte, y la persecución de los testigos de los crímenes, producen el desplazamiento forzado que, con el paso del tiempo y el recrudecimiento de esas acciones, involucra al resto del país (Alfonso, 2014,pp. 243-325).

$\mathrm{El}$ cruce de fuego entre grupos armados ocasiona el desplazamiento masivo de la población residente, por lo general, se agrupa para emprender el éxodo hacia la cabecera municipal más próxima, en busca de resguardo y protección temporal. La amenaza selectiva ocasiona el desplazamiento de personas y familias específicas, y el grupo familiar se dirige a la cabecera más próxima cuando, así como las familias víctimas del desplazamiento masivo, abriga la esperanza de retornar a su parcela. En cambio, entre quienes deciden desplazarse hacia las metrópolis prevalece la idea del cambio permanente de residencia, y entre ellos se encuentra un buen número de familias cuyos miembros han sido testigos de los crímenes y, por ello, han sido víctimas de sus afrentas (Alfonso, 2015, pp. 36-58). Las metrópolis son las principales receptoras de esta población desplazada, pues allí es posible reconstruir un proyecto de vida, aunque en un hábitat diferente. En las metrópolis también ocurren procesos de desplazamiento violento, originados por el desarrollo de economías ilegales, así como de prácticas predatorias asociadas a la renovación del acervo inmobiliario, en las que grupos criminales se alían con políticos, funcionarios de la administración local y de la policía (Pérez y Velásquez, 2013, pp. 463 y ss.; Galindo, 2018).

La informalidad urbana cumple la función de acogida habitacional de la población desplazada no cubierta por programas nacionales y 
distritales, entablándose relaciones de reciprocidad, positiva o negativa, en el submercado de alquiler (Sáenz, 2015, p. 289), a partir de vínculos de amistad, parentesco o garantía de un tercero. En ausencia de tales vínculos, o debido a conflictos intra e interfamiliares en los inquilinatos, sobreviene un segundo desplazamiento forzado que lleva al afectado a habitar en la calle.

\section{EXTERNO}

Fenómenos como la inexistencia de garantías del Estado a los derechos civiles de las personas, la inestabilidad económica y la amenaza de grupos armados paraestatales a etnias y comunidades frágiles, ocasionan el miedo, el hambre y el desarraigo de amplios contingentes de población que engrosan una diáspora a la espera de refugio en una nación amistosa que los reciba con brazos abiertos. La estrechez del mercado de trabajo local y la aversión a las sociedades multiculturales se perciben a ojos de los refugiados como las principales barreras para insertarse amablemente en la sociedad receptora. La discriminación laboral torna a los menos calificados en objetos de explotación, mientras que la xenofobia y el racismo los confina a los extramuros de las metrópolis, y la ausencia de vínculos de amistad y de parentesco los fragiliza a diario, en un contexto de vida difícil que pone en duda el propósito fundante de la Declaración Universal de los Derechos Humanos que "promete a todas las personas unos derechos económicos, sociales, políticos, culturales y cívicos que sustenten una vida sin miseria y sin temor" (Naciones Unidas, 2015, p. vii).

La segregación residencial confina a la mayoría de los desplazados a lugares inhóspitos, donde el miedo latente ocasionado por la posibilidad de la extradición es atenuado por la solidaridad entre personas que afrontan la misma situación, como ocurre en Lavapiés, barrio de Madrid que acoge a la diáspora senegalesa (Barroso, 2018). En la isla de Lampedusa el riesgo de deportación por parte de las autoridades italianas es mayor para los africanos que para los provenientes del Medio Oriente (Oller, 2017), por ejemplo. Los tratos crueles, inhumanos y degradantes que se prohíben en el artículo $5^{\circ}$ de la Declaración desde 1948 son los que afloran a diario, y la vida en la calle queda como alternativa de sobrevivencia a quienes buscan refugio y no gozan de amparo estatal ni de vínculos amistosos que hagan más llevadera su vida. 


\section{EL CONSUMO DE PSICOACTIVOS ¿DETERMINANTE O PALIATIVO?}

E1 sentido común sugiere que los habitantes de calle lo son por ser drogadictos, puesto allí se tolera la venta y el consumo de los fármacos. El uso y el abuso de psicoactivos que, inevitablemente deteriora el semblante y la conducta, refuerzan esta idea hasta degradarla en el uso común del calificativo "desechable" o "marginal". Pero cuando se exploran las razones de la adicción a las drogas es una idea derivada de un mal sentido común. Habitar en la calle implica exposición al hambre, a los vaivenes del clima por vivir a la intemperie, especialmente al frío, y a los avatares de la llegada del día y de la noche, además del miedo a las amenazas de muerte provenientes de las "manos negras", de los promotores de la obscena "limpieza social" o de sus compañeros de desgracia.

Nieto (2011) intentó identificar los principales predictores del nivel de consumo de drogas en el ciclo vital de habitantes de calle de Bogotá, así como las posibles diferencias de consumo entre niños y adolescentes que viven en las calles de Bogotá y algunas ciudades de Brasil. Las características de los habitantes de calle varían en el tiempo y, por ello, la identificación de los predictores de los problemas de salud y comportamientos de riesgo que afectan a esta población es muy compleja. La definición de droga ha sido histórica, convencional o institucional. "No existe una fórmula química o una característica física que abarque las diferentes sustancias que hoy en día se consideran drogas, y algunas de ellas, en culturas indígenas o en la antigua Grecia, fueron consideradas como medicinas u objetos rituales"(Nieto, 2011, p. 51). En el Manual Diagnóstico y Estadístico de Trastornos Mentales, todo consumo de sustancias psicoactivas indica la presencia de un cuadro de trastorno mental asociado, mientras que la Organización Mundial de la Salud define el uso nocivo de drogas como un patrón de consumo de sustancias psicoactivas que causa daños a la salud, el cual puede ser físico o mental" (ibíd.). Los términos salud y enfermedad mental están relacionados con una amplia discusión sobre lo que se considera normal y patológico. Nieto concluyó que los habitantes de calle, tanto infantes como adultos, durante su vida en la calle consumen drogas, enfrentan problemas cognitivos y enfermedades mentales como depresión, trastorno bipolar o esquizof renia, $\mathrm{y}$ diferentes formas de violencia.

El tránsito de la noche al día es percibido por los habitantes de la calle de manera diferente que por quienes gozan del confort de un 
lugar de habitación confiable, lo que hace irregular la producción de serotonina a la que sobrevienen los estados depresivos. Los pacientes medicados se tratan con ansiolíticos, hipnosedantes y antidepresivos, mientras que los habitantes de calle se automedican, recurriendo a sustitutos, con resultados como la somnolencia prolongada a la luz del día, y efectos colaterales como la laceración de la mucosa, el deterioro de las vías respiratorias y estados depresivos post-consumo. El hambre y el frío, así como el dolor, se enfrentan con sustancias inhibitorias de las funciones del sistema nervioso central, cuyos efectos se demoran cuando esas sustancias no ingresan al torrente sanguíneo, como las que inhalan y fuman los habitantes de calle por su bajo costo.

La hostilidad del ambiente callejero hacia sus habitantes consuetudinarios que se ha descrito es la que los conduce a la adicción a sustancias psicoactivas, con cuyo consumo buscan engañar al sistema nervioso central para inhibir los dolores y aflicciones que padecen. Elster señala que "la adicción es artificial y no universal; de hecho, es un accidente de la interacción entre el mecanismo de recompensa cerebral, que evolucionó para otros propósitos, y ciertas sustancias químicas"(2001,p. 191). Añade que las facultades cognitivas del adicto se entorpecen y la percepción de la exterioridad se altera, de modo que en su conducta pueden primar la excitación y el ansia de consumo sobre el rechazo y la hostilidad de los demás. Es muy probable que, en tal estado, las personas sufran alteraciones del cortisol que les acarreen pérdida de peso y de tono muscular, agotamiento persistente y malestares estomacales, así como otros síntomas asociados al estrés.

\section{REDES DE TRATA DE PERSONAS}

El sometimiento de personas en situación de desamparo e inferioridad física a la voluntad de terceros organizados, que emplean la fuerza o la coacción, para lucrarse de esa situación, es un fenómeno creciente en el que se conjugan los determinantes del desamparo y su expresión hoy más palpable -el éxodo forzado-con el interés de la delincuencia organizada por diversificar sus mercados. La mercantilización del ser humano desamparado, en inferioridad física o mental, o sugestionable, es tanto o más lucrativa que cualquier otra actividad ilegal, con un rasgo que las diferencia de las demás: la degradación sistemática de la dignidad del ser humano. Los habitantes de calle son uno de los grupos más expuestos a la acción mercantilizadora de las redes de trata de personas, que establecen reglas de sometimiento como el proxenetismo, y de disciplina como la entrega de los dividendos de 
la mendicidad o del tráfico de psicoativos que, cuando se violan, dan lugar de escarmientos, como el homicidio del transgresor.

\section{ESTIGMATIZACIÓN, ABANDONO Y RECHAZO DEL HABITANTE DE CALLE EN ALGUNAS METRÓPOLIS DEL CONTINENTE}

Los habitantes de calle, también llamados "sin hogar", no son algo exclusivo de los países en desarrollo. Existen en toda metrópoli, con mayor o menor intensidad, así haya diferencias de origen social, estructura de edades, salud física y condición mental.

Nueva York tiene unos 8,8 millones de habitantes. A comienzos del segundo trimestre de 2018 se registraban 62.498 personas sin hogar, entre ellas 15.176 familias con 22.801 niños, que dormían en el Sistema de Refugios municipales. En su mayoría afro-americanos (58\%), seguidos por latinos (31\%), blancos (7\%), y asiáticos (menos del 1\%); se desconoce la raza o etnia del 3\% (Coalition for the Homeless). Según Bowery Mission, "cerca de 4.000 personas duermen en las calles de Nueva York, en el sistema de trenes o en otros espacios públicos" (s.f.), lo que, para esa organización, es solo una parte ínfima del problema, pues la mayor parte de los sin hogar, al resguardarse en los refugios, permanecen ocultos o invisibles. Entre las causas aducidas para habitar en la calle se encuentran: enfermedades mentales, abuso de drogas, problemas médicos sin tratamiento, eventos traumáticos, violencia y abuso, carencia de una vivienda accesible y dificultad para mantener un empleo.

En Estados Unidos existen “organizaciones formadas por personas que han estado sin techo y algunas que han vivido en indigencia, [que promueven] la formación de redes sociales [para que] logren hacer causa común en la solución de sus problemas, lo que incide desde el ámbito más simple desde lo local hasta el más complejo, o nacional" (Núñez, 2001, p. 162). En 2006 el Estado de Nueva York emitió una orden para que las personas sin hogar fueran sacadas a la fuerza de la calle. La orden encontró resistencia no solo de los mismos habitantes de calle sino también entre autoridades de la ciudad de Nueva York por la preocupación por el uso de la fuerza, que solo se puede ejercer en caso de peligro inminente o enfermedad mental. Los adultos mayores decían que no querían compartir el espacio con drogadictos y que buena parte de los allí presentes debían estar en una institución mental (Chicago Tribune, 2016).

Fuentes y Flores (2016) estudian el fenómeno en Ciudad de México. Consideran que se tiende a atender las consecuencias y no sus 
causas, y encuentran que existen relaciones de solidaridad entre los habitantes de calle por la condición que comparten. Los lazos que crean no solo abarcan personas en su misma situación, sino -como en otras ciudades- también con animales "en su mayoría perros, los cuales también han sido abandonados y se encuentran en la calle, creando así una relación de cuidado y fidelidad el uno del otro" (ibíd., p. 175). Según un informe de 2017 , la población que habita en la calle aumentó en un $25 \%$ con respecto a 2016 , de 3.500-4.000 personas a más de 5.000, debido principalmente a la migración interna y externa (Zamarrón, 2017). Dada la situación problemática de esta población, en octubre de 2016 el Senado de la República propuso instrumentar un protocolo interinstitucional de atención integral a "personas en riesgo de vivir en calle e integrantes de las poblaciones callejeras en la delegación Cuauhtémoc, debido a las presuntas denuncias de violaciones a los derechos humanos de la población callejera derivados de los operativos instrumentados en la demarcación por el jefe delegacional" (Senado, 2016; Gaceta LXIII/2PPO-45/67148).

Con unos 28 millones de personas contando su área metropolitana (10 millones en la ciudad), el reporte de la Secretaría de Desarrollo Social de México sobre personas en situación de calle que presenta el Instituto de Asistencia e Integración Social de la Ciudad (IASIS) destaca, entre los resultados preliminares del censo de 2017, 4.354 personas en el espacio público y 2.400 en albergues públicos o privados. $\mathrm{E} 187,3 \%$ son hombres y el 12,7\% mujeres. E1 1,9\% corresponde a niñas y niños, el 3,74\% a personas mayores de 60 años. Las causas por las que se suman a la población callejera son: problemas familiares (39\%), económicos (28\%), adicciones (14\%); un 55\% padece problemas mentales. E1 34\% dijo que permanece en la calle por no tener otra opción, el 10\% lo eligió, el 6\% no acepta los servicios que se le ofrecen, un $6 \%$ dice que por otros motivos y un $5 \%$ por ser discriminados y excluidos (IASIS, 2017). El censo de esta población se preparó durante más de ocho meses y se espera realizar cada dos años como parte de un ejercicio de justicia social para saber si las políticas públicas para este sector han sido adecuadas.

Quito tenía casi 2.645.000 habitantes en 2017, cuando se estimó que unas 3.500 personas vivían en estado de mendicidad. La mayor proporción $(37,1 \%)$ se localizaba en el centro histórico, seguida de la zona Eloy Alfaro (17,5\%) y de La Mariscal (12,7\%). La mayoría son adultos $(69,7 \%)$ y adultos mayores $(11,2 \%)$, en su mayoría varones y de población mestiza $(63,8 \%)$, seguida por indígenas $(21,2 \%)$ ( $E l$ Telégrafo, 2017). Por otro lado, había 4.694 personas “con experiencia 
de vida en calle", de las cuales el Patronato Municipal San José acoge 2.781. La mendicidad se agravó en 2006 cuando el centro psiquiátrico San Lázaro, que funcionaba en el centro, se cerró y varios de sus pacientes no fueron reubicados y quedaron en la calle (Jácome, 2017).

En 1978 la Unesco declaró a Quito patrimonio cultural de la humanidad, distinción que ha aprovechado, como otras ciudades, para promocionar el turismo (Del Pino, 2010, p. 57; citado por Vaca, 2014, p. 11). Debido al control del Distrito Metropolitano para conservar el patrimonio y a la regulación del espacio público, "muchas de las actividades como el comercio informal, las ventas ambulantes y el pedir caridad en las calles del centro se prohíben" (Vaca, 2014, p. 18). Los adultos mayores en situación vulnerable son atendidos principalmente por instituciones religiosas, organizaciones no gubernamentales y organizaciones privadas. Según Vaca, "la institución que representa al Estado en la ciudad de Quito es el Municipio, el mismo junto con la Fundación Patronato se encuentra ejecutando el proyecto Erradicación Progresiva de la Mendicidad en el Distrito Metropolitano de Quito, este programa trabaja con niños, niñas y adolescentes, jóvenes, adultos mayores y personas con capacidades especiales" (ibíd., p. 13). Los ancianos que son abandonados por sus parientes, además de vivir en la calle son estigmatizados y enfrentan prejuicios que profundizan la "problemática de violencia estructural que tiene que vivir este grupo marginado, pues al habitar el centro histórico deben entrar en la dinámica de control ejecutada por parte del Municipio de Quito" (ibíd., pp. 17-22), pues su presencia obstruye el turismo.

Un fenómeno simultáneo que se presenta en el centro histórico de la ciudad es el del trabajo sexual, que debido a un proceso de reordenamiento urbano y recuperación del casco colonial realizado entre 2001 y 2002, en el cual se clausuraron casas de tolerancia y se planeó reubicar a las trabajadoras sexuales, llevó a que 450 optaran por ofrecer sus servicios allí. Su reubicación tardía, que comenzó en 2006, con acciones coercitivas y sin la infraestructura adecuada, ha llevado a que gran parte de ellas laboren en las calles en condiciones de inseguridad, estigmatización, discriminación social, y perseguidas por las autoridades (Álvarez y Sandoval, 2013).

En el Gran Buenos Aires habitan unos 12,8 millones de personas, y Buenos Aires unos 2,9 millones. El censo realizado por 40 organizaciones con apoyo del Ministerio Público, el Consejo de Organizaciones de la Defensoría del Pueblo y la Presidencia de la Auditoría General, instituciones de la Ciudad Autónoma de Buenos Aires, produjo un informe que señala que en 2016 "el Gobierno de la 
Ciudad dijo que había 876 personas en esa situación [de calle], casi lo mismo que en el 2012 y 2014, y apenas unas 100 personas menos que en 2015 (924)" (Proyecto 7, 2017). En 2017 la cifra se elevó a 1.066 personas según el Gobierno de la Ciudad. Dicho informe muestra que, por la tendencia del Estado a ignorar e invisibilizar la problemática, se denunció al gobierno para revisar el dato registrado y llevar a cabo un relevamiento anual junto con organizaciones de la sociedad civil. Debido a la negativa del gobierno se llevó a cabo el Primer Censo Popular de Personas en Situación de calle (PSC).

Como resultado, se censaron 4.394 PSC, 3.800 adultas, y las 594 restantes niñas, niños y adolescentes (13,5\%). Entre los menores de 18 años, 45\% son mujeres. E1 73\% de los menores de quienes se obtuvo información va a la escuela y cursa el nivel inicial, primario y secundario. E1 93\% de los adultos tiene algún nivel de instrucción: el $54 \%$ completó primaria, el $15 \%$ secundaria y un $2 \%$ superior completa. La mayoría es de origen porteño (62\%), seguida de otras provincias (25\%) y países limítrofes (12\%). Entre los motivos para llegar a la calle los principales son problemas familiares $(41,5 \%)$ y dificultades económicas $(34,9 \%)$, solo un $10 \%$ de quienes respondieron dice que por adicción a drogas; otras causas son haber estado privados de la libertad y problemas de salud mental. E1 informe señala que el $80 \%$ duerme en la calle y que un año atrás 235 de esas personas no vivía allí, lo que es un indicio del riesgo vivir en la calle para otras personas (ibíd.). E1 70\% ha sido víctima de una o varias formas de violencia social o institucional y en general se percibe un patrón de estigmatización justificador de violencia. Entre las redes de apoyo que les dan ayuda hay instituciones religiosas, fundaciones, organizaciones de la sociedad civil y grupos de amigos.

Las estadísticas del Ministerio de Desarrollo Social de Chile indican que en 2012 había 12.255 PSC en sus ciudades. Berroeta y Muñoz (2013, p. 4) estiman que el promedio de permanencia es de 5,8 años y que el 84\% eran hombres. La Región de Valparaíso es la segunda en cuanto a PSC, en las metrópolis de Valparaíso y Viña del Mar el mayor contingente pertenece al grupo de 25 a 59 años de edad (67,9\%), el 67\% respondió que tenía ingresos por algún trabajo, el $56 \%$ pernocta en la vía pública y el 37,9\% es PSC debido a problemas familiares. Existe un gran temor a perder la vida a manos de grupos neonazis, por la disputa del espacio público (Berroeta y Muñoz, 2013, pp. 12 y ss.). 


\section{LOS HABITANTES DE CALLE EN BOGOTÁ}

Los resultados del VII censo de habitantes de calle muestran que hay 9.538 personas en tal condición. Resultados anteriores revelan la persistencia del fenómeno -en 2011 se censaron 9.614, en 2007 8.385 y en 2004 10.077-, y la precariedad de las políticas materia de prevención. ¿Cuál es el contenido de las políticas? La primera parte de esta sección trata esta cuestión, la segunda explora los resultados de las entrevistas directas del último censo para proponer medidas que cualifiquen el ciclo mortal por el que atraviesan.

\section{VAIVENES DE LAS POLÍTICAS E INCLINACIÓN AL ASISTENCIALISMO}

El análisis de las políticas de las dos últimas décadas para enfrentar el fenómeno de los habitantes de calle se concentra en su contenido y su enfoque consignados en los planes de desarrollo distritales. No se analizan los planes financieros, debido a que no hay asignaciones específicas para los habitantes de la calle sino para el conjunto o subconjunto de planes y programas destinados a población vulnerable.

1998-2001: Por la Bogotá que queremos, de Enrique Peñalosa. En el capítulo sobre interacción social, que incluye el mejoramiento de la educación, de la calidad y la cobertura de los servicios de salud y de los servicios a grupos vulnerables, se encuentra el mejoramiento de la calidad y la cobertura de servicios a grupos vulnerables, dirigido a población en condiciones de pobreza crítica y exclusión social, prioritariamente niños, ancianos y habitantes de la calle. Se proponía diseñar acciones y estrategias diferenciadas para cada grupo, y adelantar acciones como el pasaporte vital para indigentes. Entre sus metas estaba atender a esa población con programas de prevención y protección, y establecer centros de asistencia integral para niños y demás habitantes de la calle.

2001-2004: Bogotá para vivir todos del mismo lado, de Antanas Mockus. Uno de los objetivos del plan era el de justicia social, consistente en mejorar el acceso de personas en situación de alta vulnerabilidad a mínimos de nutrición, salud, educación y habitación. Para este objetivo se propusieron sistemas de identificación de la población vulnerable, generar procesos de aprendizaje y auto ayuda de los beneficiarios, y generar condiciones mínimas de nutrición, salud, educación, habitación e infraestructura urbana. Como parte de este objetivo, el programa Bogotá Ciudad Fraterna buscaba atender a niños, jóvenes y habitantes de la calle, además de personas con limitaciones físicas y mentales con el fin de fortalecer vínculos familiares, comunitarios 
y sociales. Entre las metas del programa estaba la de aumentar los cupos de protección para el reintegro a sus familias y grupos sociales de niños, jóvenes, adultos mayores y habitantes de la calle. En materia de nutrición se proponía atender a niños, mujeres en gestación, adultos mayores y ciudadanos de la calle. $\mathrm{Y}$ en salud realizar atenciones ambulatorias, de urgencias, hospitalizaciones y de odontología para personas pobres y vulnerables.

2004-2008: Bogotá sin indiferencia, un compromiso social contra la pobreza y la exclusión, de Luis Eduardo Garzón. En el eje social del plan se propuso luchar por la inclusión social como forma de materializar los derechos económicos, sociales y culturales, implementando un sistema integral de protección y seguridad social, y considerando la alimentación como un derecho fundamental. Su propósito era mejorar la calidad de vida, reducir la pobreza y la inequidad y se enfocaba en las personas, grupos y comunidades en situación de pobreza y vulnerabilidad. Sus políticas fueron: 1) protección, promoción y restablecimiento de derechos; 2) alimentación como derecho fundamental; 3) ejercicio pleno de los derechos de la infancia; 4) juventud con oportunidades; y 5) equidad en el acceso a servicios sociales. Se propuso crear un Sistema Integral de Protección y Seguridad Social orientado por el Consejo Distrital de Política Social.Junto con la garantía del derecho fundamental al alimento se priorizaban la infancia, los jóvenes, las mujeres gestantes y lactantes, los adultos mayores y los discapacitados, aunque sin referencia expresa a la población habitante de la calle. Los programas del eje social eran: 1) Bogotá sin hambre (comedores infantiles y comunitarios); 2) salud para la vida digna (para grupos y comunidades en situaciones de pobreza, vulnerabilidad, alto riesgo, enfermedad, desplazados y discapacitados); 3) restablecimiento de derechos e inclusión social, enfocado en poblaciones cuyos derechos han sido vulnerados, en especial víctimas de violencia intrafamiliar y sexual.

Pese al énfasis social, solidario y humano de este plan, las referencias a la población de la calle son muy limitadas y no planteó programas ni proyectos específicos al respecto. De este modo la atención de esta población queda diluida en los programas acabados de mencionar, siendo el más pertinente el de restablecimiento de derechos e inclusión social.

2008-2012: Bogotá positiva, para vivir mejor, de Samuel Moreno. La equidad y la solidaridad fueron, junto con una perspectiva de derechos, los principios de política pública y acción de este plan que se enfocaba en personas y comunidades en desventaja manifiesta frente 
al ejercicio de sus derechos, en particular la niñez, juventud y adolescencia y discapacitados. Uno de los objetivos de este plan fue Una ciudad de derechos, cuyo propósito era garantizar condiciones de vida digna, seguridad alimentaria, nutrición, salud, educación, bienestar social, ambiente, vivienda, cultura, recreación y justicia, en especial a personas y grupos en condiciones de riesgo y vulnerabilidad. Entre los programas que desarrollan este objetivo estratégico están: 1) Garantía de aseguramiento y atención en salud; 2) Bogotá bien alimentada; 3) Alternativas productivas para la generación de ingresos para poblaciones vulnerables enfocado en mujeres y jóvenes. Entre sus metas se propuso reducir el porcentaje de población bajo la línea de pobreza y bajo la línea de indigencia; específicamente, aumentar los afiliados al régimen subsidiado de salud, dar apoyos alimentarios diarios a población en inseguridad alimentaria y nutricional, especialmente a la población vulnerable.

En relación con la población habitante de la calle, el plan se propuso garantizar y restablecer los derechos de la infancia y la adolescencia en condiciones de vulnerabilidad, para lo cual propone bajo el lema "Ninguno sin familia" las siguientes metas:

- Lograr que ninguno viva en la calle, restituyéndolo a la familia;

- Reducir la tasa de habitantes en calle a 11 por 10.000 habitantes;

- Atender 1.322 niño(a)s de la calle garantizando el derecho a la educación, alimentación y desarrollo personal;

- Operar 4 unidades de protección integral de paso, sin habitación, para 570 infantes habitantes de la calle; y,

- Operar 5 unidades de protección integral de paso, sin habitación, para 2.100 jóvenes habitantes de la calle.

Como se observa, sin ser un plan especialmente "social" en sus objetivos, es más detallado que los anteriores en cuanto a las metas relacionadas con la población que habita en la calle.

2012-2016: Bogotá Humana, de Gustavo Petro. Entre los objetivos del plan se encuentra el de reducir todas las formas de segregación. Su prioridad era la infancia y la adolescencia, y la estrategia para atender estos objetivos fue la reducción de la segregación y la discriminación. Entre los objetivos específicos se destaca el de "reconocer y garantizar el ejercicio, restablecimiento y reparación de los derechos de toda la ciudadanía" enfocado en los distintos grupos vulnerables.

El programa Territorios saludables y red de salud para la vida desde la diversidad se orientó a población vulnerable: víctimas del conflicto armado, minorías étnicas, personas mayores, afros, desplazados, discapacitados, población LGTBI, trabajadores sexuales y habitantes de 
la calle. El programa Lucha contra distintas formas de discriminación y violencia se dirigió también a la disminución de la exclusión, la segregación y la marginación de poblaciones vulnerables e incluye las "problemáticas de seguridad asociadas con los habitantes de la calle". Dentro de este último programa, el "Plan de protección diferencial para poblaciones con fragilidad social" se dirigió a habitantes de calle y personas en situación de prostitución para contribuir a su desarrollo humano integral, propiciando mejores condiciones familiares y sociales que generen cambios en sus proyectos de vida; y tratar de transformar los imaginarios relacionados con la habitación en calle y el fenómeno de la prostitución. Algunas de las metas consistían en reducir la percepción de discriminación en la ciudad; reducir el trabajo infantil; y reducir la tasa de embarazo adolescente. Específicamente buscaba proteger y atender integralmente a niños, adolescentes y jóvenes habitantes de la calle.

2016-2020: Bogotá, mejor para todos, de Enrique Peñalosa. E1 pilar Igualdad de calidad de vida de este plan se propone la ejecución de programas orientados prioritariamente a la población vulnerable y especialmente a la primera infancia. Y el de Construcción de comunidad plantea implementar programas para la construcción de territorios de paz, no violencia contra las mujeres, atención a víctimas de la violencia y condición vulnerable. En el marco de Igualdad de calidad de vida, prevé acciones integrales orientadas principalmente a las personas en condición de pobreza extrema y aquellas con mayor grado de vulnerabilidad socio-económica. Propone trascender la visión asistencialista, fortaleciendo las capacidades y el aumento de las oportunidades en función de la protección y el goce efectivo de los derechos, el desarrollo integral y la inclusión social. El plan presenta un diagnóstico que muestra un aumento del número de los habitantes de calle en la ciudad y propone como estrategia frente a este fenómeno la prevención y atención integral de la habitación en calle, de la cual se derivan las siguientes acciones:

- Abordar los factores determinantes del fenómeno a nivel individual, familiar y comunitario;

- Promover el restablecimiento progresivo de los derechos de las personas habitantes de calle para el desarrollo y fortalecimiento de las capacidades, las redes de apoyo y la transformación del estilo de vida, potenciando el ejercicio de la autonomía y promoviendo la corresponsabilidad con la ciudad; $y$,

- Adelantar procesos de prevención con poblaciones en riesgo de habitar en la calle y una atención social que incluya el contacto activo 
y permanente, además de alternativas transitorias de acompañamiento para superar las condiciones de vulnerabilidad, así como acciones de educación, cultura, recreación y deporte, formación laboral, inclusión económica y atención en salud, abordando problemas como el consumo de psicoactivos.

Lo anterior se enmarca en la Ley 1641 de 2013, que establece una política para habitantes de la calle. Allí se menciona que el Dane hará un censo para caracterizar demográfica y socio-económicamente a esta población, que servirá para establecer la línea base para implementar y evaluar la política en el Distrito. Es decir, el plan condiciona la política a la realización del censo que se hizo en 2017.

Como parte del proyecto estratégico Prevención integral del fenómeno de habitación en calle, una de las metas del plan es aumentar el número de habitantes de calle atendidos que participan en los procesos de superación de habitación en calle. Como se puede observar, el plan se enfoca en los habitantes de calle que aceptan participar voluntariamente en los programas of recidos por la administración. Se parte de un diagnóstico sobre población joven considerando que es la que tiene mayor riesgo de vincularse a redes de ilegalidad y consumo de psicoactivos. Como estrategias, el plan propone internados para restituir los derechos y el goce efectivo de derechos de infantes, adolescentes y jóvenes habitantes de calle y en riesgo de habitar en la calle. Y como estrategia transversal propone líneas de atención especializadas que atiendan los problemas de explotación sexual comercial de esta población, justicia restaurativa y mitigación del consumo.

Por último, el plan da prioridad a jóvenes víctimas del conflicto o provenientes del posconflicto, población LGTBI y mujeres vulnerables. En resumen, atención integral a población infantil, adolescente y joven que se vincule a las acciones estratégicas de la administración. Como parte de las metas se proponen dos proyectos estratégicos, Distrito Joven, que propone formar a jóvenes vulnerables en habilidades y competencias ciudadanas o laborales, y Calles Alternativas, que plantea reducir la población habitante de calle entre 8 y 28 años, mediante acciones de prevención y de reinserción a la sociedad.

\section{EL CICLO MORTAL Y EL TEMOR POR LA VIDA}

E1 derecho a la vida de los habitantes de la calle es violado de modo inusual. En condiciones normales, la etapa de desesperanza del ciclo vital de las personas aparece a los 80 años de edad, una de cuyas características es que se "entiende que el cuerpo falla y [se] necesita atención" (Rojas et al., 2014, p. 15). Al habitante de calle esto le ocu- 
rre a los pocos días de vivir a la intemperie, sin cuidados y con una ingesta irregular de alimentos, de modo que ingresa a esa etapa de manera precoz. En contra de los resultados usualmente esperados, la alteración de los sentidos y la deformación de la percepción de la realidad contraría la idea de que en esa etapa la persona adquiere "un nuevo sentido de la sabiduría y la trascendencia”. La precocidad de la desesperanza se asemeja al ciclo mortal, en el que, sin posibilidades de autorrealización, el habitante de calle está en estrés permanente por la sensación de que su vida se encuentra en riesgo, no solo por la falta de atención sino por las amenazas de quienes lo califican como "marginal" o "desechable".

\section{Gráfica 1}

Distribución porcentual del contacto familiar por sexo, Bogotá 2017

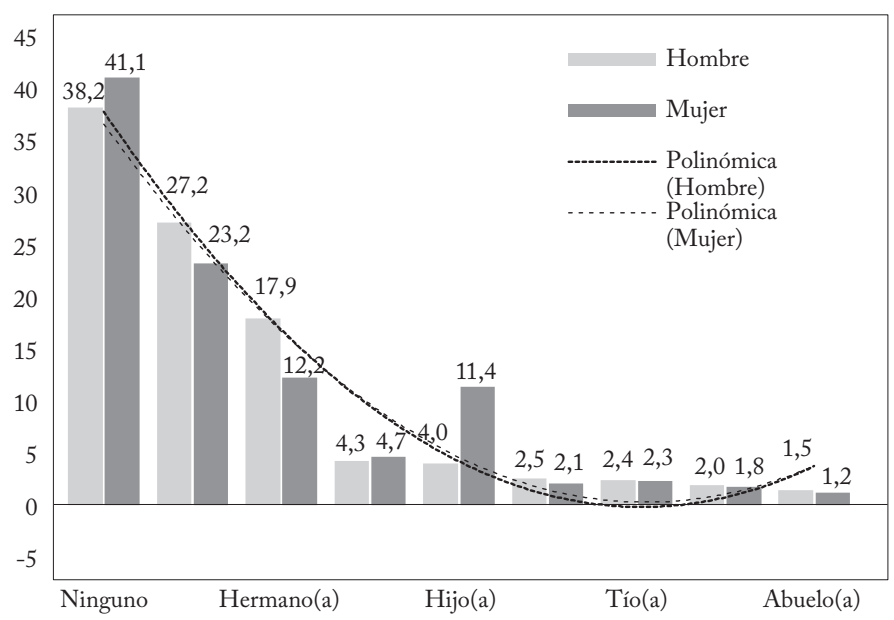

Fuente: VII Censo de Habitantes de la Calle, Dane-SDIS, elaboración propia.

El ingreso precoz a la etapa de desesperanza puede tener varios determinantes, pero el principal es la ruptura de los vínculos familiares. Una alta proporción de los habitantes de calle, un 40\%, manifestó que no tenía contacto con ningún familiar (gráfica 1), lo que indica la asociación directa de este fenómeno con la existencia de familias disfuncionales. No obstante, el hecho de que el $60 \%$ restante tenga contacto esporádico con algún familiar es un excelente indicio para que, más allá de las penas por abandono previstas en el Código Penal, las políticas procuren restablecer las relaciones familiares mediante ayuda terapéutica y, a través de ella, la reinserción simbólica y real de los habitantes de la calle. El vínculo materno es el más poderoso pues, 
tanto en el caso de los hombres como en el de las mujeres, la madre es el familiar con el que al menos una cuarta parte procura mantener contacto y, de manera complementaria, el 11,4\% de las mujeres buscan mantenerlo con sus hijos.

La estructura de la población que habita en la calle no guarda relación con la de Bogotá y menos aún con la del país, y es evidente el predominio de la población masculina (gráfica 2). La ausencia de población menor de 14 años, que sí existe, tuvo que ser detectada por observación y se identificaron 2.592 habitantes de calle, sin poder hacer entrevistas directas. Las mujeres emberá-katío, desplazadas principalmente de municipios chocoanos y risaraldenses, acostumbran habitar en la calle con los hijos, a los que enseñan tareas como la fabricación de artesanías y la mendicidad. Igual ocurre con familias de venezolanos que deambulan por las estaciones de Transmilenio a la espera de la conmiseración de los pasajeros. La relevancia de este subregistro radica en que, de un lado, la eficacia de los programas y políticas requiere registros totalmente confiables y, del otro, de que hacia los menores de edad deberían dirigirse aquellos programas que procuren su atención inmediata para que no crezcan en la calle.

\section{Gráfica 2}

Estructura poblacional, Bogotá 2017

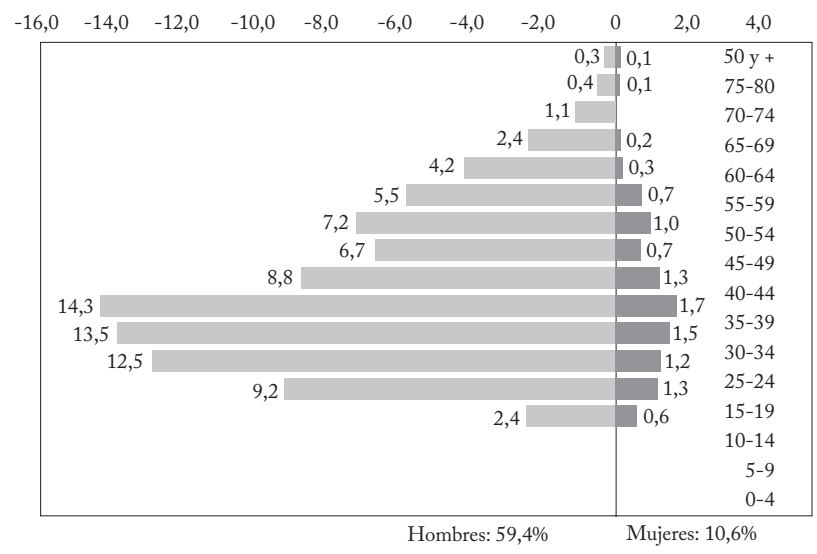

Fuente: VII Censo de Habitantes de la Calle, Dane-SDIS, elaboración propia.

E1 límite inferior de la retrospectiva de edad de llegada a la calle indica que hasta el grupo de 65 a 69 años (gráfica 3), hay personas que llegaron con cinco años de edad o menos. También revela que llegan personas de cualquier edad y los rangos se ensanchan hasta ese grupo. A partir del siguiente, la amplitud de los rangos se reduce, y 
más en los dos últimos, fenómeno singular porque personas de mucha edad (máximo 87 años) llegan a habitar en un medio hostil en la etapa de desesperanza, cuando ven a diario que sus funciones físicas y mentales son frágiles como en ninguna otra etapa de su vida. La exploración sugiere, como rasgo característico de los habitantes de calle entrevistados, que ese ciclo se hace evidente a las pocas semanas de llegar a esa situación, con independencia del grupo de edad al que pertenezcan; esto es, que el ciclo mortal de las personas, la etapa de desesperanza, se anticipa décadas al llegar a la calle.

\section{Gráfica 3}

Rangos de edad de llegada por grupo de edad, Bogotá 2017

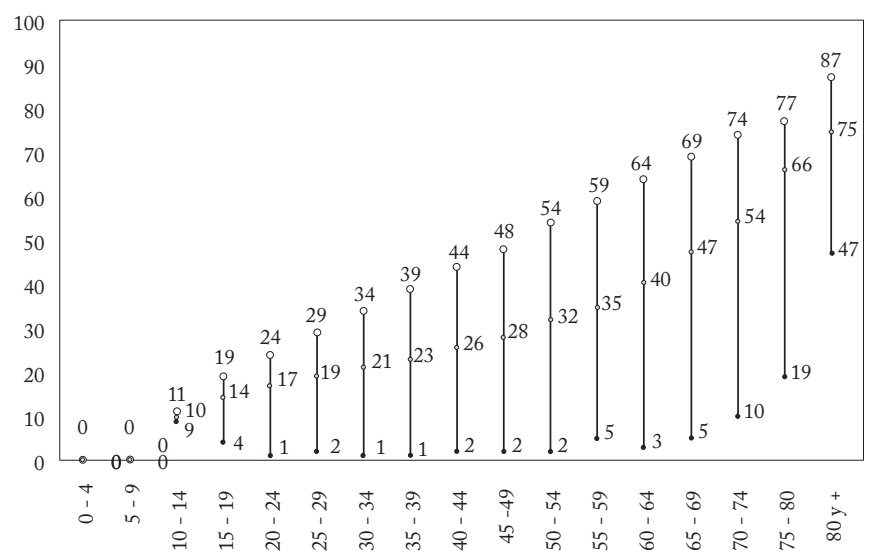

Fuente: VII Censo de Habitantes de la Calle, Dane-SDIS, elaboración propia.

Cómo expresión de la entrada en la etapa de desesperanza o ciclo mortal de los habitantes de la calle, la gráfica 4 muestra el porcentaje de vida que acumulan en promedio viviendo en tal condición. La distribución polinómica de grado dos, la que mejor se ajusta a la tendencia observada, sugiere que entre los grupos de mayor edad ese porcentaje es menor, pues la mayoría de sus miembros llega a habitar en la calle a edad avanzada. Esto indica que en este grupo de edad se presenta con mayor intensidad el desahucio en la vejez. Los hombres de 45 a 49 son los que más tiempo llevan habitando en la calle (41,6\%). La distribución de las mujeres es levemente inferior; de modo que en el ciclo mortal no hay una diferencia significativa entre sexos.

El ciclo mortal se asocia con el deterioro de la salud física y mental y, en el caso de los habitantes de calle como en ningún otro grupo de población, al estrés ocasionado por ser víctimas de insultos, golpes, amenazas, ataques con arma blanca o arma de fuego. E1 40,5\% de los 
que temen por su vida lo hacen sin haber sido víctimas (gráfica 5), pero no es un temor infundado pues saben que tarde o temprano lo serán, pues se enteran de asesinatos del pasado cercano, como el de "Comanche" en octubre de 1996, o del pasado muy próximo como los denunciados por las organizaciones no gubernamentales que los acompañan, especialmente en el centro tradicional de la ciudad.

\section{Gráfica 4}

Porcentaje de la vida como habitante de calle por sexo y grupo de edad Bogotá 2017

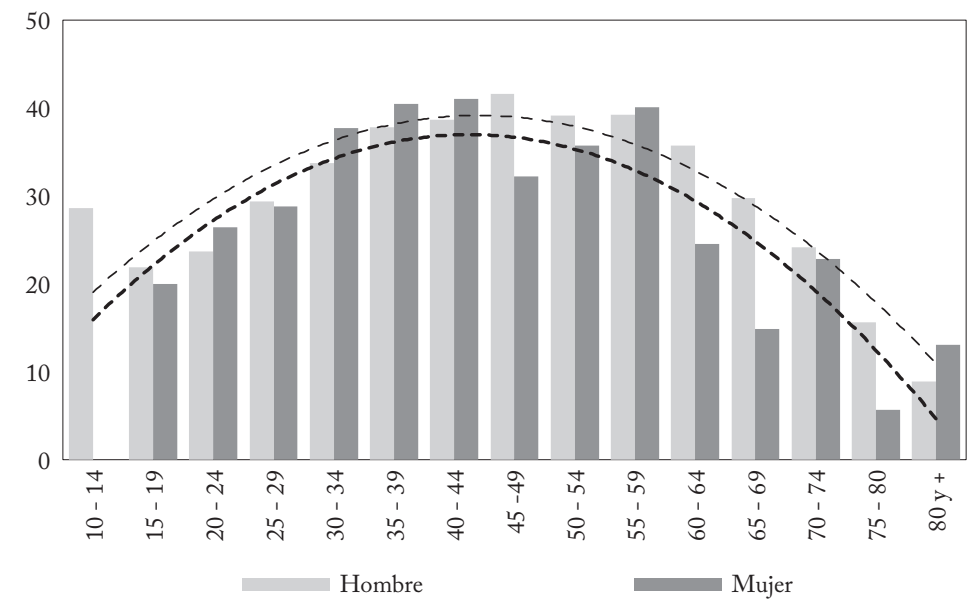

Fuente: VII Censo de Habitantes de la Calle, Dane-SDIS, elaboración propia.

La gráfica 5 revela dos paradojas: que hay habitantes de calle que aun siendo víctimas de agresiones no temen por la vida y, que a medida que estas se incrementan el temor por la vida disminuye. La respuesta que más se escucha y que conforma un sentido común errado es que esto se explica por un supuesto "hábito": una normalización de la agresión sin resultado fatal. Es errada, primero porque sí hay resultados fatales y, segundo, porque en la etapa de desesperanza las facultades cognitivas se deterioran y la percepción de la exterioridad se altera; las conductas irracionales afloran en esta etapa y se recrudecen con el consumo de alucinógenos. No es casual entonces que el consumo de alucinógenos sea proporcionalmente mayor entre los que no sienten temor por la vida que entre quienes si temen por ella (gráfica 6). 


\section{Gráfica 5}

Temor por la vida y número de agresiones mensuales, Bogotá 2017

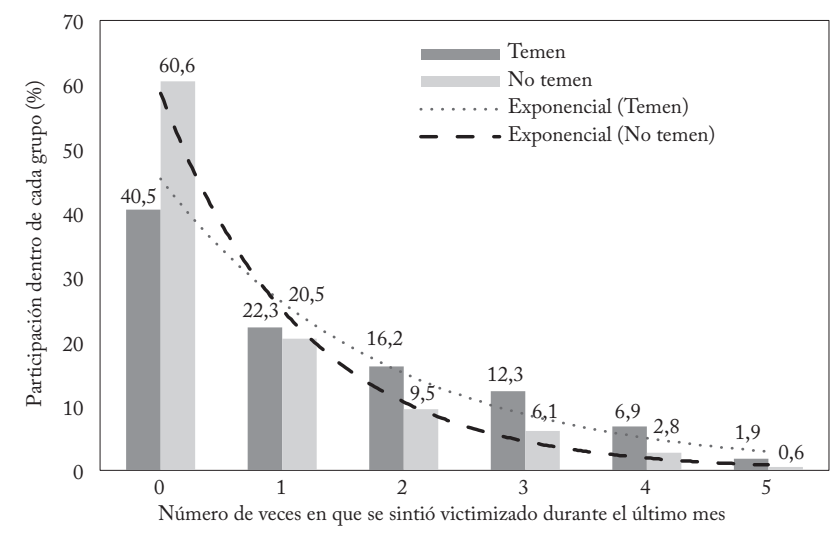

Fuente: VII Censo de Habitantes de la Calle, Dane-SDIS, elaboración propia.

\section{Gráfica 6}

Temor por la vida y consumo de alucinógenos, Bogotá 2017

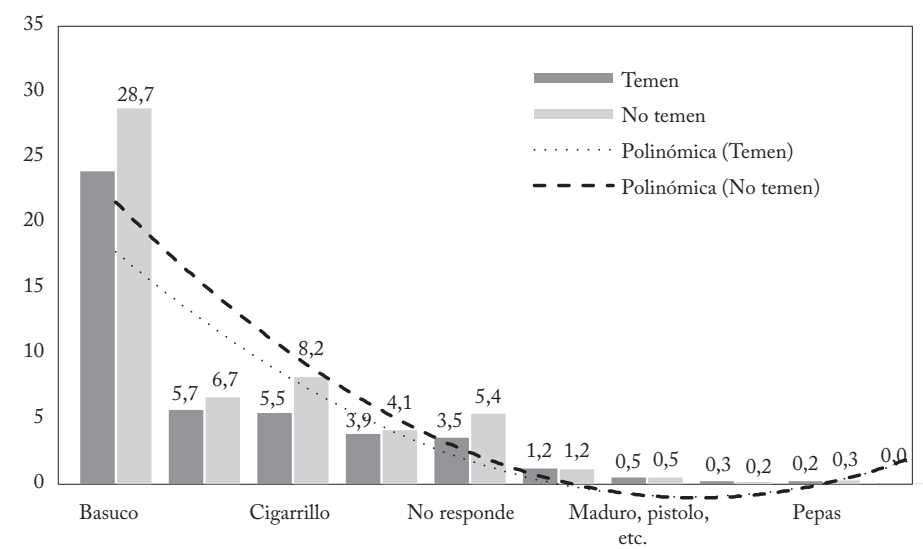

Fuente: VII Censo de Habitantes de la Calle, Dane-SDIS, elaboración propia.

\section{REFLEXIONES FINALES}

Entre los habitantes de calle se encuentran personas talentosas, hijos de familias disfuncionales, víctimas de modelos educativos represivos y de redes criminales dedicadas a la trata de personas, desplazados en sus lugares de origen por los violentos y por el hambre, así como adictos a los alucinógenos en desgracia.

La calle produce la sensación de emancipación de una escuela que transmite la ignorancia de profesores a alumnos, de una familia que 
los juzga como una carga y de grupos estatales y paraestatales que no los toleran. El encuentro con adictos, y con miembros de los circuitos ilegales del tráfico de alucinógenos y de personas, deriva a la postre en una ruda convivencia a la intemperie que termina confinando a unos y a otros en tales circuitos.

E1 deterioro urbanístico de ciertas zonas centrales de la ciudad propicia la aglomeración de quienes mejor expresan el deterioro social resultante de la desigualdad, los habitantes de la calle. "Cinco huecos", "el Cartucho"y "el Bronx” son los lugares más emblemáticos de Bogotá, cercanos a las sedes de los gobiernos nacional y distrital, y objeto de programas de renovación urbana que, con gran discontinuidad temporal, erradican a sus residentes y agravan la dispersión a la que son sometidos. "Conocí la desesperanza consumiendo en el Cartucho y después en el Bronx, allí la felicidad está negada” respondió "El Cantante", quien a sus 58 años descubrió que padece epilepsia y que necesita medicación diaria. "Nada que ver con lo ajeno" es la manera como uno de sus paisanos, de 28 años de edad y 4 habitando en la calle, intenta ganar la confianza de los transeúntes del centro tradicional de Bogotá, a quienes aborda en busca de la limosna para reunir los 100 mil pesos diarios que dedica al consumo de 25 a 30 papeletas de bazuco y pagar los 5 mil pesos del rincón que ocupa en un inquilinato. El ciclo mortal de los habitantes de calle se inicia a cualquier edad.

Estos testimonios apoyan los argumentos expuestos en el artículo, que pretenden promover análisis que contribuyan a modificar las ineficaces políticas y los fracturados modelos estatales de atención a los habitantes de la calle; y a cuestionar los erróneos lugares comunes sobre los determinantes de la habitación en la calle, su cotidianidad y sus desenlaces fatales. Quizá un propósito utópico porque, como dice Raigosa, "la gente cree lo que quiere creer, lo que reafirme sus creencias y la haga sentir más cómoda con su realidad” (Semana, 2017).

\section{REFERENCIAS BIBLIOGRÁFICAS}

Alfonso R., Ó. (2015). Persistencia del sesgo por el statuo quo en la intervención de la Corte Constitucional sobre los derechos fundamentales de la población desplazada, Colombia 2004-2014. Revista del Departamento de Geografía, 5(3), 36-58.

Alfonso R., Ó. (2014). La geografía del desplazamiento forzado reciente en Colombia y la estigmatización de la condición de desplazado en la metrópoli nacional. En Ó. Alfonso (ed.), Los desequilibrios territoriales 
en Colombia: estudios sobre el sistema de ciudades y el polimetropolitanismo (pp. 243-328). Bogotá: Universidad Externado de Colombia.

Álvarez, S. y Sandoval, M. (2013). Trabajo sexual en el centro histórico. Quito: Distrito Metropolitano de Quito.

Báez, J., González, A. M. y Fernández, C. (2013). Una propuesta para la concepción y abordaje del habitante de calle desde una perspectiva psicioanalítica. Revista CES Psicología, 6(2), 1-14.

Berroeta, H. y Muñoz, M. I. (2013). Usos y significados del espacio público en personas en situación de calle. Un estudio en Valparaíso y Viña del Mar. Revista de Psicología, 22(2), 3-17.

Carretero, R. R. y León, V. E. (2009). Indigencia trashumante. Despojo y búsqueda de sentido en un mundo sin lugar. México DF: UNAM.

Elster, J. (2001). Sobre las pasiones: emoción, adicción y conducta humana. Barcelona: Paidós.

Fuentes-R., G. y Flores-C., F. D. (2016). La indigencia de adultos mayores como consecuencia del abandono en el Estado de México. Papeles de Población, 22(87), 161-181.

Gómez, U. C. (2015). El habitante de calle en Colombia: presentación desde una perspectiva social-preventiva. Actualidad Jurídica, [www. uninorte.edu.co/documents/4368250/13012565/Octava+Edicion.pdf/ aea8200d-213e-44a2-95b8-c56c2ef0ee48].

Kahneman, D. y Tversky, A. (1973). On the psychology of prediction. Psychological Review, 80(4), 237-251.

Mendivelso, D. (2017). Incidencia de la jurisprudencia constitucional sobre las políticas públicas para los habitantes de calle, bajo el principio de igualdad y no discriminación. Tesis de Maestría en Derecho Público. Bogotá: Universidad de la Salle-Universidad Konstanz.

Navarro, C. O. y Gaviria, L. M. (2010). Representaciones sociales del habitante de calle. Universitas Psychologica, 9(2), 345-355.

Nieto, C. J. (2011). Consumo de drogas en tres etapas de la vida de habitantes de calle en Bogotá: predictores de consumo y comparación con una muestra de población infantil y adolescente de Brasil. Tesis de Maestría en Psicología. Brasil: Universidad Federal de Rio Grande do Sul.

Nieto, C. J. y Koller, S. H. (2015). Definiciones de habitante de calle y de niño, niña y adolescente en situación de calle: Diferencias y Yuxtaposiciones. Acta de Investigación Psicológica, 5(3), 2162-2181.

Núñez, G. S. (2001). Estados Unidos: Pobreza Urbana y Orgnaizaciones comunitarias. Problemas del desarrollo, 3(124), 149-170.

Palma, R. (2007). La indigencia en la ciudad de Caracas, un enfoque periodístico. Trabajo de grado. Caracas: Universidad Católica Andrés Bello.

Pérez, S. B. y Velásquez, M. C. (2013). Procesos de renovación urbana, brecha de rentas del suelo y prácticas predatorias: el caso del polígono de intervención del Plan Centro. Colombia, centralidades históricas en trasformación, 8, 464-490.

Restrepo, A. A. (2016). El ser humano al límite: una mirada reflexiva al habitante de calle. Drugs and Addictive Behavior, 1(1), 89-100. 
Rojas, K., Gómez, J. F. et al. (2014). El ciclo vital individual. Programa de Educación Continua en Pediatría. Bogotá: Sociedad Colombiana de Pediatría.

Sáenz, A. H. (2015). A reciprocidade como marco institucional dos contratos de locação residencial: $\mathrm{O}$ casso de Patio Bonito I, um bairro popular de Bogota, na Colombia. Tese de Doutorado em Planejamento Urbano e Regional. Río de Janeiro: IPPUR-Universidade Federal do Rio de Janeiro.

Sen, A. (2011). Nuevo examen de la desigualdad. Madrid: Alianza Editorial.

Vaca, R. M. (2014). Estrategias de subsistencia del adulto mayor habitante de calle en el centro de Quito. Ecuador: Flacso.

Wilkinson, R. y Pickett, K. (2009). The spirit level: Why more equal societies almost always do better. Nueva York: Bloomsbury Press.

\section{ARTícUlos DE PRENSA}

Barroso, F. J. (2018, 19 de marzo). El ayuntamiento de Madrid supo cómo murió Mbaye tres horas antes de los incidentes de Lavapiés. El País, [https://elpais.com/ccaa/2018/03/19/madrid/1521486533_369231. html].

Chicagotribune.com. (2016, 4 de enero). La orden de NY de refugiar a los sin techo afronta desafíos. [http://www.chicagotribune.com/ hoy/ct-hoy-8530667-la-orden-de-ny-de-refugiar-a-los-sin-techoafronta-desafios-story.html].

Elcomercio.com.ec. (2017). [http://www.elcomercio.com: http://www.elcomercio.com/actualidad/puentes-albergue-habitantes-calle-quito.html].

Eltelegrafo.com.ec. (2017, 01 de abril). [https://www.eltelegrafo.com.ec/ noticias/179/11/la-calle-es-el-eterno-hogar-de-casi-3-mil-personas].

Galindo, C. (2018). El asesinato como práctica común de la policía: de la muerte necesaria a manzanas podridas. Periódico electrónico Palabras al Margen, 132. [http://palabrasalmargen.com/uncategorized/el-asesinato-como-practica-comun-en-la-policia-de-la-muertenecesaria-a-manzanas-podridas/].

Jácome, E. (2017, 29 de octubre). Nueve puentes son albergue de habitantes de calle en Quito. El Comercio, [http://www.elcomercio.com/ actualidad/puentes-albergue-habitantes-calle-quito.html].

Maier, C. (2017, 27 de junio). Una escritora antisistema. Entrevista [www.elespectador.com/entretenimiento/un-chat-con/una-escritoraantisistema-articulo-700143].

Mosquera, Sh. (2012, 17 de junio). Abandonar a papá...jno!. El Universo, [http://www.larevista.ec/orientacion/psicologia/abandonar-a-papano..].

Oller, C. (2017, 2 de junio). Lampedusa, una prisión de roca para los refugiados del Mediterráneo. [http://noticias.perfil.com/2017/06/02/ lampedusa-una-prision-de-roca-para-los-refugiados-del-mediterraneo/].

Publimetro.com.mx. (2017, 19 de julio). [https://www.publimetro.com. $\mathrm{mx} / \mathrm{mx} /$ noticias/2017/07/19/sube-25-poblacion-callejera-la-ciudadmexico.html. 
Raigosa, A. (2017). Entrevista, [http://www.semana.com/vida-moderna/ articulo/noticias-falsas-ciencia-de-comer-cuento/518343].

Zamarrón, I. (2017, 19 de julio). Sube 25\% población callejera en la Ciudad de México, [https://www.publimetro.com.mx/mx/noticias/2017/07/19/ sube-25-poblacion-callejera-la-ciudad-mexico.html].

\section{NORMAS Y SENTENCIAS}

Alcaldía Mayor de Bogotá. Acuerdo 06 de junio 8 de 1998. Plan de Desarrollo Económico, Social y de Obras Públicas para Santa Fe de Bogotá D. C. 1998-2001 “Por la Bogotá que queremos”. [http://www. alcaldiabogota.gov.co/sisjur/normas/Norma1.jsp?i=535].

Alcaldía Mayor de Bogotá. Decreto 440 de 2001. Plan de Desarrollo Económico, Social y de Obras Públicas para Bogotá D. C. 2001-2004 "Bogotá para vivir todos del mismo lado". [http://www.alcaldiabogota. gov.co/sisjur/normas/Norma1.jsp?i=3787].

Alcaldía Mayor de Bogotá. Acuerdo 119 de junio 3 de 2004. Plan de Desarrollo Económico, Social y de Obras Públicas para Bogotá D. C. 2004-2008 "Bogotá sin indiferencia. Un compromiso social contra la pobreza y la exclusión”. [http://www.alcaldiabogota.gov.co/sisjur/ normas/Norma1.jsp?i=13607].

Alcaldía Mayor de Bogotá. Secretaría de Planeación Distrital. Plan de Desarrollo Económico, Social y de Obras Públicas para Bogotá D. C. 2008-2011 "Bogotá Positiva: para vivir mejor". Balance general 2008-2012, Bogotá, diciembre de 2011, [http://www.sdp.gov.co/sites/ default/files/2008_2012_bogotapositiva_c_informefinal_a_balancegeneral.pdf].

Alcaldía Mayor de Bogotá. Acuerdo 489 de junio 12 de 2012. Plan de desarrollo económico, social y de obras públicas para Bogotá D. C. 2012-2016 "Bogotá Humana”, [www.alcaldiabogota.gov.co/sisjur/ normas/Norma1.jsp?i=47766].

Alcaldía Mayor de Bogotá. Acuerdo 645 de 2016. Plan de Desarrollo Económico, Social y de Obras Públicas para Bogotá D. C. 2016-2020 "Bogotá mejor para todos", [http://www.ipes.gov.co/images/informes/ Acuerdo_645_de_2016_plan_de_desarrollo_2016-2020.pdf].

Coalition for the homeless. (s.f). Basic facts about homelessness: New York City, [http://www.coalitionforthehomeless.org/our-programs/\#Food].

Corte Constitucional de Colombia. Sentencia C-034/05. Demanda de inconstitucionalidad contra la expresión "legal" contenida en el artículo 127 de la Ley 599 de 2000 "por la cual se expide el Código Penal”.

IASIS. 2017. Resultados preliminares Censo de poblaciones callejeras 2017, [http://189.240.34.179/Transparencia_sedeso/wp-content/ uploads/2017/Preeliminares.pdf].

Naciones Unidas. 2015 (1948). Declaración Universal de los Derechos Humanos, [www.un.org/es/documents/udhr/UDHR_booklet_SP_web. $\mathrm{pdf}]$.

Proyecto 7. (julio de 2017). A mi no me contaron: visualizar para humanizar, [http://proyecto7.org/wp-content/uploads/2017/07/Informepreliminar-1\%C2\%BA-CPPSC.pdf]. 
República de Colombia. Ley 599 de 2000 "por la cual se expide el Código Penal".

República de México. Senado, d. 1. (28 de octubre de 2016), [http://www. senado.gob. $\mathrm{mx} /$ index.php?ver $=\mathrm{sp} \& \mathrm{mn}=2 \& \mathrm{sm}=2 \& \mathrm{kid}=67148]$.

The Bowery Mission. (s.f.). [https://www.bowery.org/homelessness/]. 